\title{
Large birth size does not reduce negative latent effects of harsh environments across life stages in two coral species
}

\author{
Aaron C. Hartmann, ${ }^{1,5}$ Kristen L. Marhaver, ${ }^{2,3}$ Valérie F. Chamberland, ${ }^{3,4}$ Stuart A. Sandin, ${ }^{1}$ \\ And Mark J. A. VermeiJ ${ }^{3,4}$ \\ ${ }^{1}$ Center for Marine Biodiversity and Conservation, Scripps Institution of Oceanography, University of California at San Diego, \\ La Jolla, California 92093 USA \\ ${ }^{2}$ University of California, Merced, California 95343 USA \\ ${ }^{3}$ CARMABI Foundation, Piscaderabaai z/n, Willemstad, Curaçao \\ ${ }^{4}$ Aquatic Microbiology/Institute for Biodiversity and Ecosystem Dynamics, University of Amsterdam, Amsterdam, The Netherlands
}

\begin{abstract}
When juveniles must tolerate harsh environments early in life, the disproportionate success of certain phenotypes across multiple early life stages will dramatically influence adult community composition and dynamics. In many species, large offspring have a higher tolerance for stressful environments than do smaller conspecifics (parental effects). However, we have a poor understanding of whether the benefits of increased parental investment carry over after juveniles escape harsh environments or progress to later life stages (latent effects). To investigate whether parental effects and latent effects interactively influence offspring success, we determined the degree to which latent effects of harsh abiotic conditions are mediated by offspring size in two stony coral species. Larvae of both species were sorted by size class and exposed to relatively high-temperature or low-salinity conditions. Survivorship was quantified for six days in these stressful environments, after which surviving larvae were placed in ambient conditions and evaluated for their ability to settle and metamorphose. We subsequently assessed long-term post-settlement survival of one species in its natural environment. Following existing theory, we expected that, within and between species, larger offspring would have a higher tolerance for harsh environmental conditions than smaller offspring. We found that large size did enhance offspring performance in each species. However, large offspring size within a species did not reduce the proportional, negative latent effects of harsh larval environments. Furthermore, the coral species that produces larger offspring was more, not less, prone to negative latent effects. We conclude that, within species, large offspring size does not increase resistance to latent effects. Comparing between species, we conclude that larger offspring size does not inherently confer greater robustness, and we instead propose that other life history characteristics such as larval duration better predict the tolerance of offspring to harsh and variable abiotic conditions. Additionally, when considering how stressful environments influence offspring performance, studies that only evaluate direct effects may miss crucial downstream (latent) effects on juveniles that have significant consequences for long-term population dynamics.
\end{abstract}

Key words: Agaricia humilis; latent effects; life history; Montastraea faveolata; offspring size theory; parental effects; scleractinian corals.

\section{INTRODUCTION}

A major goal of ecology is to understand how species tolerate and acclimate to various abiotic conditions. This is particularly important in the earliest stages of life, when many organisms suffer high mortality due to an inability to tolerate environmentally induced stress (Thorson 1950, Begon et al. 2006). Reductions in offspring fitness can arise while individuals are in a

Manuscript received 25 January 2013; revised 19 March 2013; accepted 21 March 2013. Corresponding Editor: R. B. Aronson.

${ }^{5}$ Present address: Scripps Institution of Oceanography, University of California at San Diego, 9500 Gilman Drive, Mail Code 0208, La Jolla, California 92093-0208 USA.

E-mail: achartma@ucsd.edu stressful environment ("direct effects") and after they have left stressful environments or progressed to a later life stage ("latent effects"; sensu Pechenik 2006). While tolerance of offspring to a given environment can be determined by a number of factors including cellular defenses and adaptive responses (Hamdoun and Epel 2007), offspring size has long been considered an important mediator of environmental tolerance within species (Thorson 1950, Smith and Fretwell 1974, Parker and Begon 1986, Bernardo 1996).

Offspring size is primarily determined by maternal provisioning, and theory predicts that mothers have a finite pool of energy to invest in many small or few large offspring (Smith and Fretwell 1974, Parker and Begon 1986, Bernardo 1996). When mothers are able to influence the size and number of progeny they produce, 
this trade-off allows them to optimize offspring survival given their local environmental conditions ("parental effects"; Smith and Fretwell 1974, Bernardo 1996, Mousseau and Fox 1998). In poor-quality environments, large offspring tend to have higher success than smaller conspecifics (Parker and Begon 1986, Marshall et al. 2006, Allen et al. 2008), whereas size is of less or no importance in benign or extremely harsh environments (Moran and Emlet 2001, Begon et al. 2006).

Previous work has focused on the importance of offspring size while organisms are experiencing stressful conditions (i.e., direct effects; Allen et al. 2008, Marshall and Keough 2009, Burgess and Marshall 2011), leaving relatively little knowledge about whether size and experience can interactively influence offspring success after individuals move away from stressful conditions or progress to a later life stage (though see Crean et al. 2011). Despite this, a growing body of evidence is revealing that latent effects can be profound and important (reviewed in Pechenik 2006). For example, delaying larval metamorphosis can reduce subsequent fitness in salamanders and crabs (Semlitsch et al. 1988, Gebauer et al. 1999, respectively) and nutrient deprivation during early development can lead to stunted or abnormal growth in fish and birds (McCormick and Molony 1992, Merilä and Svensson 1997, respectively). Despite the pervasiveness of latent effects across many taxa, we do not know whether the benefits of extra parental provisioning can offset the negative latent effects that arise after offspring experience harsh abiotic conditions early in life.

The capacity of parental provisioning to buffer progeny from environmental stress depends intimately upon the source of stress. In most manipulative studies of the importance of parental provisioning, stresses have been generated via biotic factors such as inter- and intraspecific competition and dispersal duration (e.g., Emlet and Hoegh-Guldberg 1997, Allen et al. 2008, Marshall and Keough 2009, Burgess and Marshall 2011, Crean et al. 2011). In such situations, energy availability can provide inherent benefits to the organism (e.g., an increased ability to withstand delayed metamorphosis in non-feeding larvae). In contrast, we have a poor understanding of whether large size promotes tolerance to harsh and variable abiotic conditions such as high temperature and low salinity, despite the fact that mobile offspring commonly experience variable abiotic conditions during dispersal (Marshall and Morgan 2011). Therefore, in the present study, we determined whether offspring size influences susceptibility to latent effects of harsh abiotic conditions in two common Caribbean coral species.

Sessile marine invertebrates such as corals are particularly useful for exploring parental and latent effect theory because they produce offspring of variable size, progress through distinct early life stages, and commonly experience multiple environments prior to reaching adulthood (Pechenik 2006, Marshall and
Morgan 2011). The two coral species studied here, Agaricia humilis and Montastraea faveolata, both produce larvae of different mean sizes with a high degree of size variability within offspring cohorts. This allowed us to test for interactions between parental effects and latent effects by measuring the performance of small and large larvae of each species after exposure to either high-temperature or low-salinity environments, two abiotic factors known to negatively impact coral offspring (Edmunds et al. 2001, Vermeij et al. 2006, Randall and Szmant 2009).

Based on offspring size theory and studies of direct effects, we predicted that for each species: (1) relatively large offspring would have higher pre-settlement survival, settlement, and post-settlement survival than smaller conspecifics (i.e., evidence of parental effects); (2) larvae exposed to harsh environments would have lower settlement and post-settlement survival after being moved to a "common garden" (i.e., evidence of negative latent effects of harsh environments); and (3) relatively large larvae would suffer the least reductions in settlement and post-settlement survival after experiencing harsh environmental conditions (i.e., evidence that large larval size buffers negative latent effects).

By measuring the performance of each species in the same manner, our experiment also allowed us to test whether these species differ in their degree of susceptibility to negative latent effects, and whether the species that produces larger larvae overall suffers less severe latent effects (i.e., whether absolute offspring size determines susceptibility to latent effects). Based on offspring size theory alone, one might predict that the species with larger progeny, A. humilis, would be less prone to negative latent effects than $M$. faveolata. However, A. humilis larvae disperse for a short period (hours to days), while $M$. faveolata larvae disperse for much longer (days to months). As a result, an alternative prediction can be generated based on life history theory. The short-dispersing $A$. humilis larvae might be expected to suffer more extreme latent effects when subjected to environments significantly different from the parental environment, while the long-dispersing $M$. faveolata larvae would be more tolerant of a variety of conditions like those experienced during their longer larval phase (sensu Uller 2008).

\section{Materials And Methods \\ Collection of larvae from Agaricia humilis and Montastraea faveolata}

Agaricia humilis (low-relief lettuce coral) is a small ( $<12 \mathrm{~cm}$ in diameter), encrusting to submassive stony coral found throughout the tropical West Atlantic (van Moorsel 1983). Eggs are fertilized internally (i.e., brooded $)$ and relatively large spheroid larvae $(\sim 600 \times$ $900 \mu \mathrm{m}$ long) are released throughout the year. $A$. humilis larvae contain symbiotic dinoflagellates from birth and disperse for a short period (hours to days) before settling (van Moorsel 1983). 
Twenty-seven colonies of $A$. humilis were collected on scuba from the southeast Oostpunt region of the leeward coast of Curaçao $\left(12^{\circ} 2^{\prime} 33^{\prime \prime} \mathrm{N}, 68^{\circ} 46^{\prime} 49^{\prime \prime} \mathrm{W}\right)$. Within two hours of collection, corals were placed in individual $1-\mathrm{L}$ beakers with a constant flow of $100-\mu$ m-filtered seawater. All larvae released on the first night after colony collection were pooled on the following day to create an experimental cohort of a single age $(n=1235)$. To generate large and small size classes in roughly equal numbers, larvae were gently passed through or retained above a submerged nylon mesh filter. A range of mesh sizes was tested; a mesh size of $430 \mu \mathrm{m}$ was used for the final size class separation ( $n=712$ large, $n=523$ small). Fourteen representative larvae from each size class were photographed with a scale bar using a dissecting microscope. From these photographs, the longitudinal and transverse axes were measured (NIH ImageJ; available online $)^{6}$ and used to calculate larval volume by assuming the volume of a spheroid (van Moorsel 1983).

Montastraea faveolata (mountainous star coral) is a dominant, massive reef-building stony coral that occurs throughout the tropical West Atlantic and can grow to $10 \mathrm{~m}$ in diameter (Szmant et al. 1997). M. faveolata is a simultaneous hermaphrodite that reproduces via broadcast spawning once per year in late summer and early fall by releasing bundles containing sperm and small spherical eggs $(\sim 200-300 \mu \mathrm{m}$ in diameter). During their relatively long (days to months) dispersal period, the competent, swimming planula larvae can disperse tens to hundreds of kilometers prior to settlement (Vermeij et al. 2006).

Bundles of egg and sperm were collected from eight $M$. faveolata colonies during the annual mass spawning in Curaçao (Water Factory site, $12^{\circ} 6^{\prime} 33^{\prime \prime} \mathrm{N}, 68^{\circ} 57^{\prime} 15^{\prime \prime}$ $\mathrm{W})$. Gametes were pooled and allowed to fertilize for 120 minutes. Embryos were then sequentially diluted in $0.45 \mu \mathrm{m}$-filtered seawater (Millepore HA filter; EMD Millepore, Billerica, Massachusetts, USA) using methods adapted from Vermeij et al. (2006). After $24 \mathrm{~h}$, swimming larvae were separated into two size classes using a nylon mesh $(190 \mu \mathrm{m})$. A sample of larvae from each size class was stored in 5\% volume/volume formaldehyde for later size measurements that were conducted in the same manner as those for A. humilis.

\section{Experiment 1: Direct effects of exposure to harsh environmental treatments on survival}

Larvae of each size class were placed into one of three environmental treatments: high-temperature (36 psu, $31^{\circ} \mathrm{C}$ ), low-salinity (30 psu/85\% of ambient salinity, $28.5^{\circ} \mathrm{C}$ ), or ambient conditions (36 psu, $\left.28.5^{\circ} \mathrm{C}\right)$. Temperatures were selected to correspond with average monthly mean water temperatures in Curaçao (ambient and low-salinity treatments) and $1.5^{\circ} \mathrm{C}$ above the

${ }^{6}$ http://rsbweb.nih.gov/ij/ bleaching threshold of adult corals in Curaçao (hightemperature treatment; data available online). ${ }^{7}$ Salinity levels were selected to mimic ambient seawater conditions in Curaçao (ambient and high-temperature treatments), as well as conditions known to influence larval behavior after significant rainfall (low-salinity treatment; Vermeij et al. 2006). Salinity was manipulated by diluting seawater with sterile, deionized water. Nine replicates for each size/environmental treatment were generated by aliquoting $10 \mathrm{~A}$. humilis or $30 \mathrm{M}$. faveolata larvae into $15-\mathrm{mL}$ polystyrene conical tubes (BD Biosciences, San Jose, California, USA) that contained filter-sterilized seawater (0.22- $\mu \mathrm{m}$-Sterivex-filtered; EMD Millepore, Billerica, Massachusetts, USA). Polystyrene surfaces and highly filtered seawater were used because they delay the formation of biofilms inside the tubes and thus encourage larvae to continue to swim as they would in the water column (Vermeij et al. 2009). The number of larvae per tube was chosen to minimize density effects after Vermeij et al. (2009). Tubes were closed and haphazardly assigned to test tube racks submerged in temperature-controlled water baths (after Edmunds et al. 2001). Three water baths were used for each temperature treatment and water baths were interspersed randomly on the laboratory bench. Temperature was recorded every five minutes (HOBO Pro V2 water temperature data loggers; Onset Computer Corporation, Bourne, Massachusetts, USA) for the duration of the experiment. For A. humilis, the average temperatures among all water baths over the six-day experiment were: high-temperature treatment, $30.9^{\circ} \pm$ $0.3^{\circ} \mathrm{C}$ (mean $\pm \mathrm{SD}$ ); ambient and low-salinity treatments, $28.4^{\circ} \pm 0.3^{\circ} \mathrm{C}$. For $M$. faveolata, temperatures were: high-temperature treatment, $31.0^{\circ} \pm 0.5^{\circ} \mathrm{C}$; ambient and low-salinity treatments, $28.7^{\circ} \pm 0.3^{\circ} \mathrm{C}$. Larvae experienced a natural light cycle created by indirect sunlight and fluorescent laboratory lights that were on for $\sim 12$ hours per day.

Larval behavior was assessed by removing individual tubes from the water bath and examining them with a dim light in order to count the number of larvae alive and settled. Settlement was defined as the three-step sequence of attaching to a surface, undergoing metamorphosis, and beginning calcification. After counts, the tube cap was unscrewed for $5 \mathrm{~s}$ to allow for gas exchange, closed, and returned to the water bath. In total, tubes were outside of the water baths for $<45 \mathrm{~s}$ each. Tubes within a given water bath were haphazardly rearranged in the test tube rack on each day of data collection. For M. faveolata, three repeat counts were taken for each tube and averaged due to the high number of larvae in each tube. On the final day of observation, larvae were counted using a pipette. Behavioral measures were recorded on days 1, 2, 3, 4, and 6.

\footnotetext{
${ }^{7}$ http://coralreefwatch.noaa.gov/satellite/vs/caribbean.
html
} 
Because our experimental treatment tubes were closed and did not allow gas exchange, we evaluated whether larval respiration in the tubes led to decreased dissolved oxygen concentrations and thus created an additional source of larval stress. Using a Hach HQ40d oxygen probe (Hach, Loveland, Colorado, USA), we found that tubes with $A$. humilis larvae contained $2.4 \%$ less dissolved oxygen on average than an invigorated filtersterilized seawater control (100\% oxygen saturation) after three days. Tubes containing $M$. faveolata larvae had $0.5 \%$ less dissolved oxygen on average than an invigorated filter-sterilized seawater control after six days. Because these reductions in dissolved oxygen were small and less than measured diurnal variation in dissolved oxygen on a coral reef (Kinsey and Kinsey 1967), we concluded that it was unlikely larvae of either species experienced low-oxygen stress as a result of our experimental methods.

\section{Experiment 2: Latent effects of exposure to harsh environmental treatments on settlement}

After six days in the high-temperature, low-salinity, and ambient environmental treatments, all surviving larvae from a given size/environment were pooled in a single beaker containing filter-sterilized seawater. For $A$. humilis, 15 larvae per size/environment were dispensed into polystyrene cups with lids. Between three and five replicate cups were used per size/environment, the number of which was determined by the number of larvae that survived Experiment 1. Each cup contained $200 \mathrm{~mL}$ of $100-\mu \mathrm{m}$-filtered seawater and was maintained at $28.5^{\circ} \mathrm{C}$. Into each cup was placed a limestone settlement tile $(4.8 \times 2.2 \times 1.0 \mathrm{~cm})$ that had been cured in the ocean offshore from the CARMABI Research Station for one month, as well as two small $\left(\sim 0.25 \mathrm{~cm}^{2}\right)$ chips of crustose coralline algae (CCA), which are known to induce settlement in this species (Morse et al. 1994, Raimondi and Morse 2000). The number of larvae that were alive or settled in each dish was recorded daily for four days. A blue light and yellow filter (NightSea LLC, Bedford, Massachusetts, USA) was used to visualize larvae and settlers via their fluorescent properties.

Concurrently, A. humilis larvae that were released on the same day that the settlement experiment began were placed in an analogous settlement experiment with 30 larvae per cup in three replicates to assess settlement immediately after release (i.e., these larvae were not subjected to six days in the environmental treatments). This experiment used no size separation and the number of larvae that were alive or settled in each cup was measured daily for four days. The duration of the larval period is a commonly studied causal agent of latent effects (Pechenik 2006); thus this experiment provided a secondary means for examining latent effects in this species that was independent of larval size and environmental treatment.
For $M$. faveolata, all surviving larvae from a given size/environment were pooled in a single beaker containing filter-sterilized seawater. Thirty larvae from each size/environment were allocated randomly in triplicate petri dishes that contained $30 \mathrm{~mL}$ of 0.45 $\mu \mathrm{m}$-filtered seawater. For this species, settlement induction was encouraged by adding CCA "extract" (crushed CCA slurry filtered through a $0.22-\mu \mathrm{m}$ Sterivex filter). These experiments were conducted with glass slides instead of limestone tiles because $M$. faveolata larvae will readily settle on glass slides and petri dishes, and because settlers are extremely difficult to observe on limestone (A. Hartmann, personal observation). The number of larvae that were alive or settled was recorded daily in each replicate for 14 days. The $M$. faveolata settlement experiment was run longer than the $A$. humilis experiment because of the relatively longer larval period of M. faveolata (van Moorsel 1983, Vermeij et al. 2006).

\section{Experiment 3: Latent effects of exposure to harsh environmental treatments on in situ post-settlement survival}

To measure post-settlement survival of $A$. humilis, all tiles with settlers from Experiment 2 were attached to a submerged PVC scaffold on the reef $(n=1-11$ for settlers that experienced the six-day larval period, $n=$ 13-23 for settlers with no larval period). The majority of settlers were oriented perpendicular relative to the sea floor to minimize smothering from sediments. The scaffold was arranged so that settlers were $\sim 0.5 \mathrm{~m}$ above the reef substrate at the average depth from which the parent colonies were collected $(\sim 3.5 \mathrm{~m}$ depth). The number of live settlers was counted on scuba using a blue light and yellow filter 7, 18, 25, 38, 78, and 145 days after out-planting. A comparable experiment was attempted for $M$. faveolata but two-thirds of the settlement dishes were lost shortly after out-planting due to strong surge. The limited data remaining were left out of this report.

\section{Statistical analyses}

A maximum-likelihood estimation approach was used to evaluate the best-fit model for survival and settlement (Hilborn and Mangel 1997). Briefly, a binomial error distribution was used to estimate the most supported probability of a given success (alive, settled) given a set number of trials (larvae in a replicate) for a group of size/environments. A suite of multiparameter models was generated for particular groupings of distinct size/ environments (ranging from no difference among any size/environments to distinct parameters for each size/ environment; see Appendix), and best-fit parameters were estimated using maximum likelihood. The relative fits of competing models were determined using one of two methods. When comparing models containing different numbers of parameters, we employed likelihood ratio tests (for nested models) or the Akaike Information Criterion (for non-nested models). When 
A) Agaricia humilis

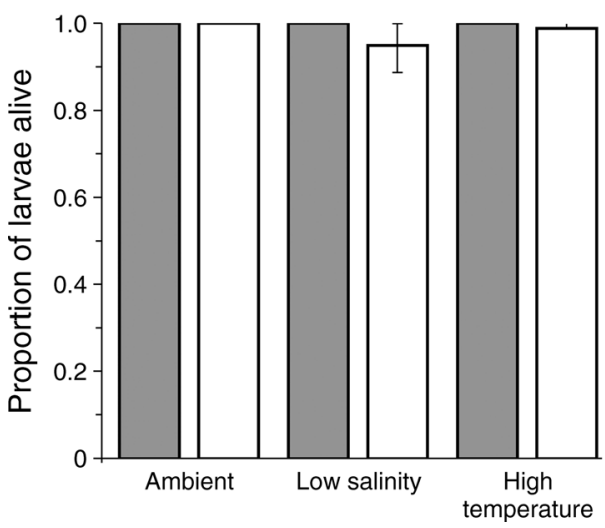

B) Montastraea faveolata

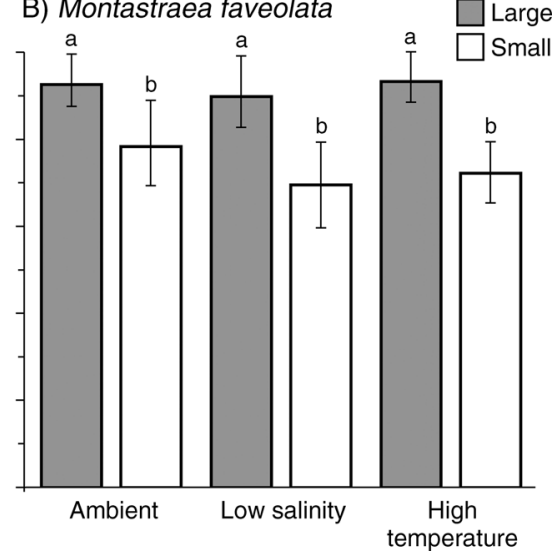

FIG. 1. The effect of parental investment and harsh environmental treatments on survival of (A) Agaricia humilis and (B) Montastraea faveolata coral larvae from colonies on the leeward coast of Curaçao. One day after birth, larvae were separated by size into large (gray bars) and small (white bars) larval cohorts and subsequently exposed to one of three environments: ambient, low-salinity, and high-temperature treatments. Values represent the mean proportion of larvae alive after six days (shown with arcsine square-root transformed $95 \%$ confidence intervals). Different lowercase letters above each bar represent statistically distinct groups as determined by maximum-likelihood estimation.

comparing models with equal numbers of parameters, assessment of relative fit was based on an assumption of equal Bayesian priors, from which statistical $P$ values were generated (Vermeij and Sandin 2008, Vermeij et al. 2009, Marhaver et al. 2013 and Appendix: Table A1). When total mortality was observed within a replicate, that replicate was left out of maximum-likelihood model testing and data representations as the data violated the assumption of independence of individuals.

Tiles with settled A. humilis were placed on the reef scaffold with unequal numbers of individuals due to the fact that there were unequal numbers of settlers by size/ environmental treatment. For statistical analyses we assumed that there were no density-dependent effects of settler number on survival on a given tile due to the extremely small surface area of tile covered by settlers $(<3 \%$ on the densest tile).

\section{RESUlts}

\section{Experiment 1: Direct effects of exposure to harsh} environmental treatments on Agaricia humilis larvae

After they were separated into size classes for experiments, the mean volume of small $A$. humilis larvae $\left(0.093 \pm 0.022 \mathrm{~mm}^{3}, 95 \% \mathrm{CI} ; n=11\right)$ was $\sim 32 \%$ less than the volume of large larvae $\left(0.137 \pm 0.040 \mathrm{~mm}^{3} ; n=\right.$ $10 ; P<0.01)$. The coefficient of variation equaled 0.34 among all larvae. After six days, the probability of larval survivorship was not equal across size/environmental treatments (null rejected; $P<0.05$; Appendix: Fig. 1A and Table A2). Small larvae raised in harsh environments (i.e., low-salinity and high-temperature environmental treatments; data combined) had lower survival than all other size/environments (two-parameter model; $P<0.05$ ), although this model could not be statistically differentiated from models where large larval size, large larvae in the ambient environmental treatment, and all larvae in the ambient environmental treatment experienced higher survival relative to all other size/environments $(P>0.05$; Appendix: Table A2). In aggregate, the models show higher survival for large larvae and larvae in the ambient environmental treatment, and lower survival for small larvae and larvae in high-temperature or low-salinity environmental treatments. Survival was high overall, as $99 \%$ of large larvae and $94 \%$ of small larvae survived across environmental treatments. Negligible settlement $(<4 \%)$ was observed during the sixday experiment. Total mortality was observed in $17 \%$ of the replicates. When the structure of these "crashes" was evaluated, it was found that total mortality was greatest for small larvae in the low-salinity environmental treatment (Fisher's exact test; $P<0.05$ ).

\section{Experiment 2: Latent effects of exposure to harsh environmental treatments on settlement} of A. humilis larvae

When provided with cured substrate, newborn $A$. humilis larvae were nearly twice as likely to settle compared to the relatively older larvae that experienced our environmental manipulation experiment (no larval period vs. large and small larvae in the ambient environmental treatment combined; Fig. 2A; $P<$ 0.05). Small larvae and those that had experienced high-temperature or low-salinity environmental treatments had significantly lower settlement than large larvae that had experienced the ambient environmental treatment $(P<0.05$; Fig. $2 \mathrm{~A}$ and Appendix: Table A3), suggesting there were both parental effects and latent effects of harsh larval environments in this species. The effects of larval size and environment on settlement were independent and multiplicative: regardless of environment, small larvae were $42 \%$ less likely to settle than large larvae, and regardless of size, larvae raised in high- 

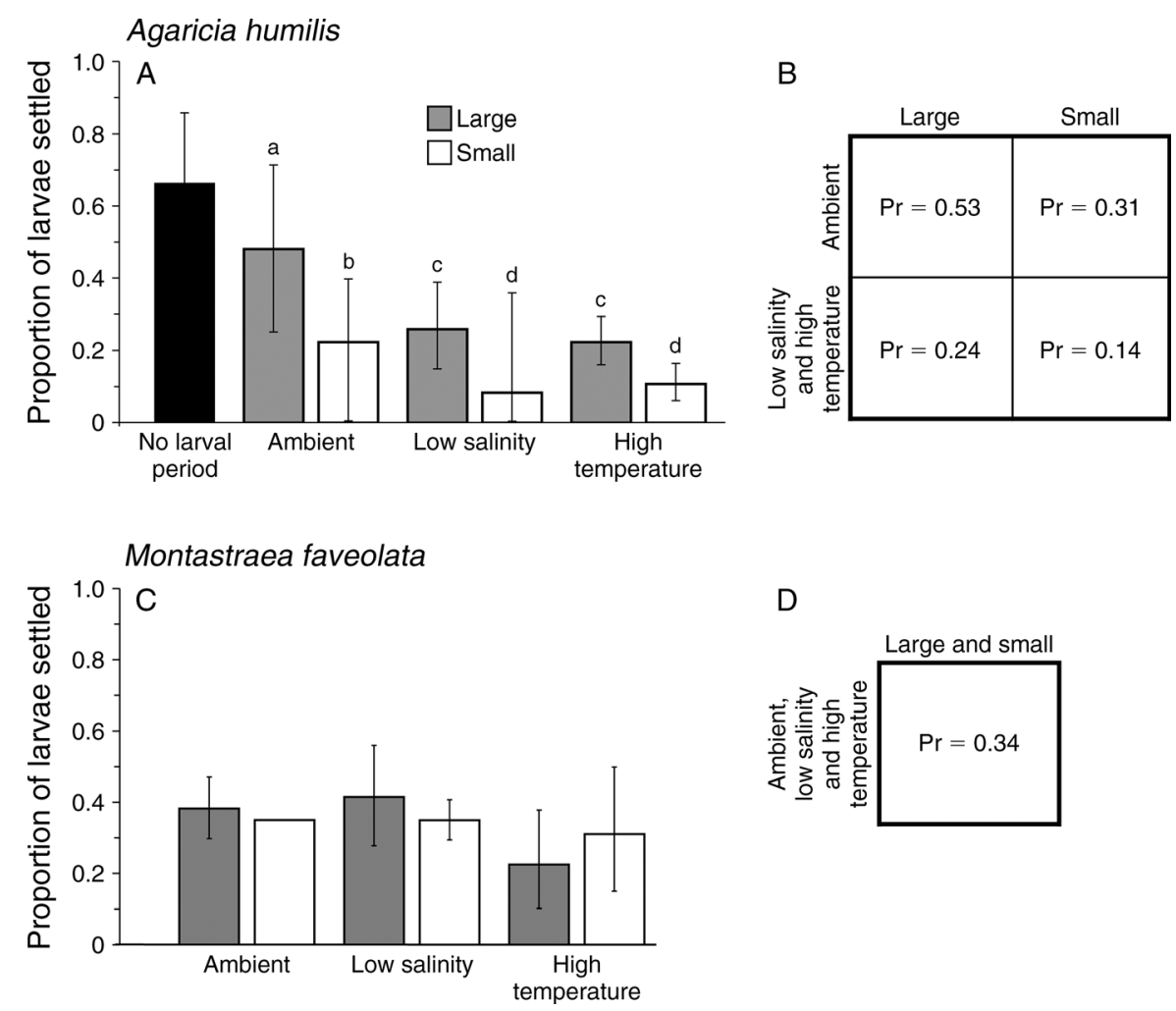

FIG. 2. The effect of parental investment and harsh environmental treatments on settlement success of (A) A. humilis and (C) M. faveolata larvae. After size separation and six days in ambient, low-salinity, and high-temperature treatments, larvae were placed in ambient conditions and provided with settlement substrate. Values represent the mean proportion of larvae settled after four days for $A$. humilis and 14 days for $M$. faveolata (shown with arcsine square-root transformed $95 \%$ confidence intervals) of individuals that survived the environmental treatment experiment. Different lowercase letters above each bar represent statistically distinct groups as determined by the best-fit maximum-likelihood estimators depicted in panel (B) for A. humilis and (D) for M. faveolata, where settlement probabilities (Pr) are also reported. The black bar in panel (A) denotes settlement of $A$. humilis larvae that were exposed to positive settlement cues the day after they were born (i.e., they did not experience six days of larval environmental treatments). These data were not included in statistical analyses.

temperature and low-salinity environments (pooled) were $54 \%$ less likely to settle than those raised in the ambient environmental treatment (Fig. 2B). Overall, $86 \%$ of all settlement occurred in the first 24 hours of the four-day experiment.

\section{Experiment 3: Latent effects of exposure to harsh environmental treatments on in situ post-settlement survival of A. humilis settlers}

After Experiment 2, all tiles with settled A. humilis were returned to the reef. A large die-off occurred between days 18 and 38 , with only $24-64 \%$ of settlers surviving per tile (Fig. 3A). After this die-off, $\sim 58 \%$ of the settlers from large larvae that experienced the ambient environmental treatment survived, while settlers from all other size/environments had survivorship of $<20 \%$. On day 78 , survivorship was significantly different among size/environments (null rejected; $P<$ 0.05; Appendix: Table A4), with consistent evidence that large size/ambient environment settlers survived better than small size/ambient environment settlers. On day $145,28 \%$ of large size/ambient environment settlers remained alive compared to $3 \%$ on average for all other size/environmental treatments; the statistical conclusions for this time point were comparable to those for day 78. Of the newborn larvae that were allowed to settle immediately, $17 \%$ survived to day 145 compared to $16 \%$ of the settlers that were subject to the six-day larval experiment (both size classes combined, ambient environmental treatment only; Fig. 3B). This difference was not significant $(P>0.05)$.

\section{Experiments 1 and 2: Direct and latent effects of exposure to harsh environmental treatments on Montastraea faveolata larvae}

After they were separated into size classes for experiments, the mean volume of small $M$. faveolata larvae $\left(0.006 \pm 0.001 \mathrm{~mm}^{3}, 95 \% \mathrm{CI} ; n=9\right)$ was $\sim 65 \%$ less than the mean volume of large larvae $(0.017 \pm 0.004$ $\left.\mathrm{mm}^{3} ; n=10 ; P<0.001\right)$. The coefficient of variation equaled 0.60 among all larvae. After six days in each of the three environmental treatments, large larvae had significantly higher survival than small larvae $(88.3 \%$ and $70.4 \%$, respectively) regardless of environment $(P<$ 


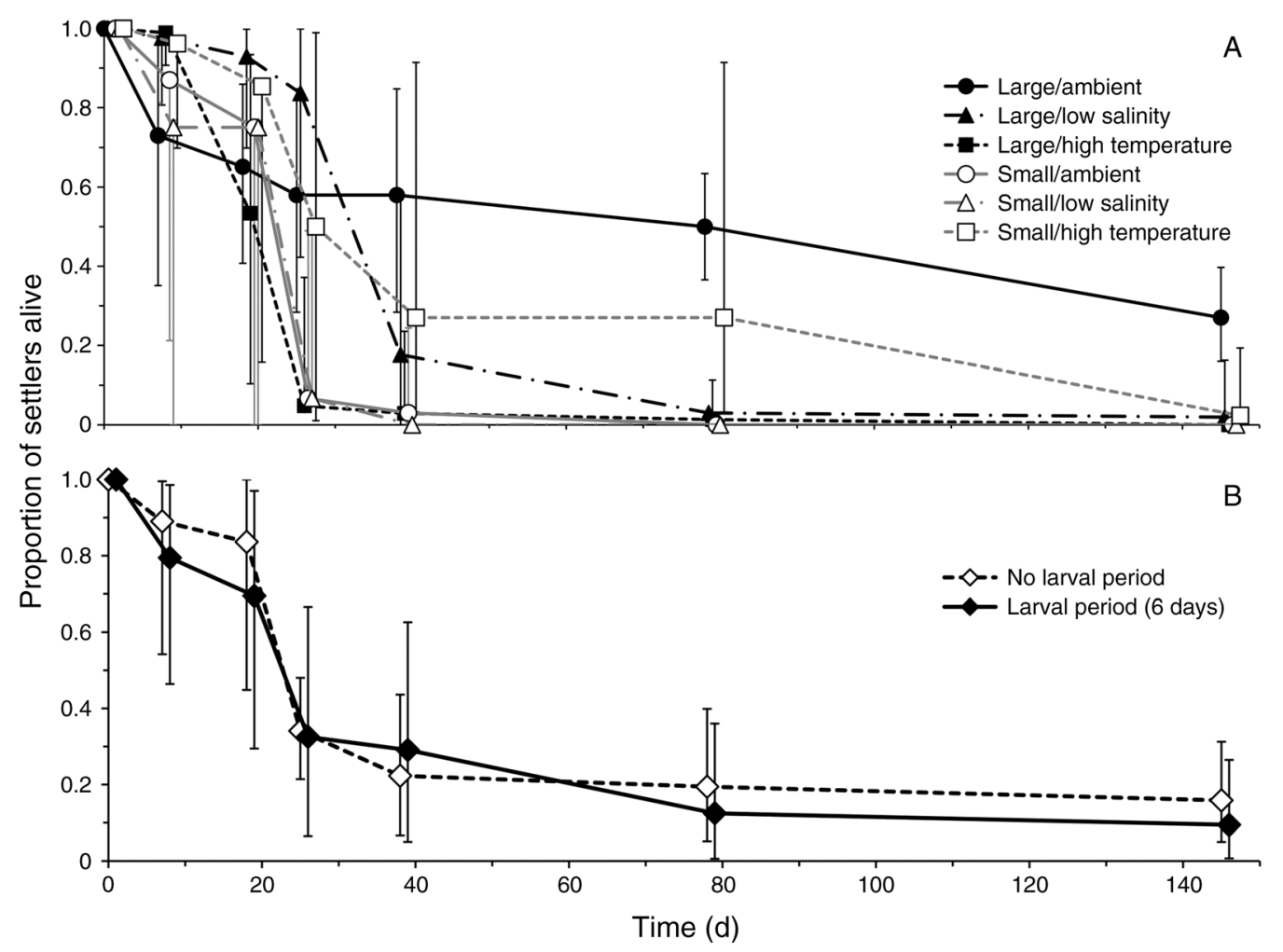

FIG. 3. The effect of parental investment, harsh environmental treatments, and larval duration on in situ post-settlement survival of Agaricia humilis. Settlers were outplanted on the reef at approximately the same depth from which parent colonies were collected. Values represent mean proportions of original settlers that were alive (shown with arcsine square-root transformed $95 \%$ confidence intervals) over a 145-day time period based on (A) their birth size and larval environment or (B) the length of the larval period they experienced.

0.001; Fig. 1B and Appendix: Table A2), consistent with expectations based on parental effects. Fewer than $7 \%$ of replicates experienced total mortality and these crashes were left out of maximum-likelihood estimations. Incidence of total mortality was greatest in the lowsalinity environmental treatment $(P<0.01)$.

After larvae were returned to ambient conditions and exposed to CCA extract, settlement of large $M$. faveolata larvae was significantly greater than settlement of small larvae after six days $(P<0.001)$, although settlement was equal across size classes by day $14(P>0.05$; Fig. 2C, D and Appendix: Table A3). At no point did larvae incubated in the high-temperature, low-salinity, or ambient environmental treatments show different settlement patterns, cumulatively demonstrating no evidence for parental effects or latent effects of harsh environmental treatments on settlement in M. faveolata.

\section{Discussion}

\section{Latent effects of harsh larval environments were more pronounced in Agaricia humilis}

We saw no direct effects of harsh environments on larval survival in M. faveolata and found weak statistical support in A. humilis. In the latter, larval survival was $\geq 94 \%$ in all size/environmental treatments. In contrast, the latent effects of harsh larval environments were more notable and therefore have larger ecological significance. Settlement of $A$. humilis was, on average, reduced by $55 \%$ in both harsh environments, and post-settlement survival after five months was $28 \%$ for large larvae raised in the ambient environmental treatment compared to $3 \%$ among all other size/environments. This suggests that the effect of experiencing harsh environments during the larval stage was acute months later for A. humilis, well beyond the typical time horizon for most studies of larval performance. In contrast, exposure to harsh pre-settlement environmental treatments did not reduce subsequent settlement of $M$. faveolata once placed in ambient conditions (post-settlement survival measurements were not successful), suggesting that this species does not suffer negative latent effects of harsh larval environments on settlement.

The latent effects we observed due to the low-salinity environmental treatment are particularly interesting as they highlight distinct responses to abiotic stressors in closely related marine organisms. In the barnacle Balanus amphitrite, low-salinity stress during the larval stage reduced post-metamorphic growth rates (Thiyagarajan et al. 2007). In contrast, low salinity caused 
negative direct effects but no post-metamorphic latent effects in three gastropod species (Diederich et al. 2011). In our study of two coral species, M. faveolata showed no latent effects of the low-salinity treatment on settlement, whereas A. humilis showed decreased settlement and post-settlement survival. Our results further demonstrate that the latent effects of low-salinity conditions on marine larvae can differ both within and among taxa.

We conclude that $A$. humilis larvae are less tolerant of harsh environments than $M$. faveolata larvae. The latter were surprisingly robust to the harsh environments in our experiments. This is particularly interesting because A. humilis larvae are perceived to be more resilient than M. faveolata larvae due to a higher degree of parental care (brooded rather than broadcast spawned), larger larval size, and a higher propensity of adults to tolerate marginal environments such as bays and areas with high human disturbance (Knowlton 2001). Despite this, our observation of negative latent effects of harsh environments in A. humilis larvae is consistent with past studies showing that larvae of the small brooding coral Favia fragum had lower total metamorphosis after exposure to elevated temperatures (Randall and Szmant 2009), and that settlers of the brooding coral Porites asteroides had lower post-settlement survival after experiencing elevated temperatures prior to metamorphosis (Ross et al. 2012).

A majority of past studies of latent effects have examined the role of biotic factors (e.g., swimming behavior, delayed metamorphosis, reduced feeding), rather than abiotic factors as the causal agents of latent effects (reviewed in Pechenik 2006). In these studies, the most common treatment was delayed metamorphosis. In our initial experiment, in which larvae were subjected to harsh environmental treatments and denied settlement cues or substrates, we delayed settlement in all size classes and environmental treatments in order to examine the latent effects of abiotic environments. However, we were also able to determine whether delayed settlement itself caused negative latent effects in A. humilis. We found that delaying settlement by six days reduced final settlement by $48 \%$ but had no effect on post-settlement survival, suggesting that $A$. humilis larvae suffer negative latent effects of delayed settlement as a reduced ability to settle, but not in the form of reduced post-settlement longevity. Interestingly, our study also revealed that high-temperature and lowsalinity environments are comparable, if not stronger, drivers of negative latent effects (on settlement) than delayed settlement in this species $(55 \%$ vs. $48 \%$ reduction, respectively). Consistent with our observations, cyprid larvae of the barnacle Balanus amphitrite exhibited negative latent effects of low salinity on postmetamorphic growth that were as severe as latent effects caused by delayed metamorphosis (Thiyagarajan et al. 2007).

\section{The role of life history in determining species-specific tolerance of harsh environments}

Expectations based on offspring size theory were not observed across species, as harsh environments caused negative latent effects in larvae of $A$. humilis, which are relatively large, but not in larvae of $M$. faveolata, which are relatively small. Instead, this distinction is supported by life history theory based on the different reproductive biology and dispersal characteristics of each species. The physiological plasticity necessary to tolerate a range of environments is energetically costly and will be selected against in a homogenous environment, such as that experienced by a species with short-distance dispersal like A. humilis (Parsons 1998). During their long larval period, M. faveolata have a greater likelihood of encountering a higher variety of environments than do short-dispersing brooded larvae; thus selection should favor more robust tolerance of a wider range of larval environments in M. faveolata (Strathmann et al. 2002, Uller 2008).

Parental effects that increase per-offspring success, such as large offspring size, are strongly selected for when parents can "predict" the environment their offspring will experience. Thus, selection for increased parental investment per offspring can be particularly strong in short-distance dispersers (Uller 2008, Crean and Marshall 2009). The A. humilis parent colonies used in this study did not experience the harsh environments that their larvae did, and thus their offspring were exposed to an environmental "surprise." $M$. faveolata parent colonies, on the other hand, are expected to produce larvae that can survive environments unlike their own, given the species' greater dispersal period and distance. This could explain why, while $A$. humilis larvae are much larger in size, our experiments showed that their tolerance of stressful environments was much lower than larvae of $M$. faveolata.

The propensity for latent effects in A. humilis offspring has the potential to create a ratcheting-down effect where experiencing harsh larval conditions carries over into later life stages, even after the condition has been escaped or has reverted to a less-stressful state. In contrast, the recruitment of new individuals of $M$. faveolata appears to depend more heavily on the quality of larvae, as offspring were unaffected by the harsh larval environments used here. This suggests that the health of adult M. faveolata in a given source population plays a greater role in determining the survival of offspring than do the effects of environmental conditions during dispersal.

\section{Parental effects were evident in both coral species}

We observed evidence of parental effects in both coral species, the magnitude of which differed between species and among life stages. Large $M$. faveolata larvae had $\sim 25 \%$ higher survival than small larvae during the presettlement period, while survival of large A. humilis larvae was only $5 \%$ greater than small larvae during the 
same period. At the start of the settlement phase, small M. faveolata larvae exhibited initial delays in settlement, but eventually settled at the same rate as larger conspecifics, while total settlement by small $A$. humilis larvae was significantly lower than settlement by large larvae. Thus, our data suggest that offspring size is of greater importance for planktonic survival in $M$. faveolata and for settlement ability in A. humilis.

Energy exhaustion can reduce settlement success in a number of marine taxa and may explain the reduced settlement we observed in small A. humilis larvae (Emlet and Hoegh-Guldberg 1997, Pechenik 2006). Metamorphosis in marine invertebrates can be energetically taxing (Videla et al. 1998) and proportionally more so for small larvae within a species (Wendt 2000). Thus energy reserves in small $A$. humilis larvae might have been insufficient for the completion of metamorphosis despite high survival during the pre-metamorphic period ("living dead" hypothesis; Raimondi and Morse 2000). The fact that newborn coral larvae contain greater energy reserves (as storage lipids) than week-old conspecifics (Harii et al. 2007, Figueiredo et al. 2012) can explain why newborn $A$. humilis offspring that were given metamorphosis cues immediately after being released had approximately double the total settlement of larvae that experienced six days of conditioning in our study.

In contrast, $M$. faveolata settlement may not have been limited by energy availability in our experiments, given the relatively long dispersal period of this species. Upon exposure to settlement cues after six days of larval conditioning, $86 \%$ of all observed settlement by $A$. humilis occurred within one day, while only $13 \%$ of all observed settlement by $M$. faveolata occurred within the first six days of the 14-day experiment, demonstrating that the latter species can delay settlement even when conditions favor it. Interestingly, when A. humilis larvae were exposed to settlement cues on the day they were born, $97 \%$ of all observed settlement occurred within two days. Thus, individuals that experienced a six-day larval period (i.e., a relatively long larval period for the species) were no more desperate to settle than newborn larvae, though newborn larvae had higher settlement overall. This suggests that $A$. humilis larvae settle rapidly when they encounter settlement cues and this response is independent of age, while $M$. faveolata larvae delay settlement even in the presence of positive cues.

\section{Offspring size did not mediate latent effects of harsh environments}

Contrary to our predictions, offspring size did not influence the magnitude of negative latent effects of harsh larval environments. Small M. faveolata larvae demonstrated delayed settlement compared to large, but no overall reduction in settlement after experiencing harsh environments. A. humilis experienced both parental and latent effects, yet they were independent and additive rather than synergistic. Furthermore, small larval size and harsh larval environments reduced settlement probability in nearly equal amounts in $A$. humilis, suggesting their approximately equal importance in determining offspring success.

Begon et al. (2006) proposed that environments can be classified as "offspring size-sensitive" in which large offspring have higher survival or "offspring sizeinsensitive," in which offspring size is of little consequence. Because the environment experienced by parent colonies in our study was benign in nature, it is likely that individuals provisioned and otherwise influenced their larvae as they would in an offspring size-insensitive habitat. As a result, the responses we observed to harsh larval environments likely reflected the inherent role of offspring size in buffering harsh conditions, rather than benefits to larvae that were gained from adaptive parental provisioning. Because this inherent benefit of size was independent of the response to harsh environmental conditions, this suggests that large size per se does not increase the ability of these coral progeny to withstand harsh abiotic environments.

In highly variable environments, some species increase offspring size variability as an adaptive strategy to optimize the likelihood that some individuals survive (Crean and Marshall 2009). This is analogous to the long dispersal period of $M$. faveolata, and we would therefore expect less selection for a specific/consistent larval size in this species and greater overall variability in size. We did in fact observe this, as the coefficient of variation of $M$. faveolata larval volume was nearly double that of $A$. humilis ( 0.60 vs. 0.34 , respectively).

\section{The importance of life history and environmental tolerance for community dynamics}

The observed benefits of large birth size in both coral species studied here suggest that these progeny will be overrepresented in settler/recruit populations compared to initial larval cohorts. Overall, the parental effects we observed demonstrate that, in addition to larval abundance, offspring size partially determines the probability of recruitment success in a given area for each species. Therefore, assuming a static relationship between adult abundance, fecundity, and recruitment success does not account for crucial larval size-dependent factors that will affect population structure and dynamics of settlers and recruits.

Our results showed that species-specific responses to harsh environments are independent of offspring size in these corals. Extending our results to other species we theorize that organisms with high local recruitment resulting from short larval periods are more susceptible to latent effects after experiencing harsh (i.e., locally unique) environments, while species with long dispersal periods are less prone to such forms of latent effects. In order to test whether dispersal distance per se affects susceptibility to negative latent effects, one would need to evaluate species with similar life histories (e.g., compare among multiple brooding species). 
Our findings are interesting given that, due to anthropogenic disturbance, many coral reefs are transitioning from adult communities dominated by massspawning, slow-growing species like $M$. faveolata to communities dominated by smaller, brooding species like A. humilis (Green et al. 2008, Burman et al. 2012). While these transitions are largely driven by die-off of adults, it is unclear if and to what extent recruitment failure affects or accelerates these changes in community structure (Szmant 1991, Hughes and Tanner 2000, Vermeij et al. 2011). The life history strategy of species like $M$. faveolata (wide dispersal, low per-offspring survival) is likely to result in extremely low recruitment, yet with increasing environmental variability or persistent change, there may be an increase in recruitment opportunities due to chance (sensu Chesson and Warner 1981), or perhaps due to greater tolerance of stressful and variable environments. Indeed, while overall recruitment has declined on the island of Curaçao, where our study took place, the relative representation of settlers of spawning species vs. brooding species has increased in the last 40 years (Vermeij et al. 2011). This suggests a discordance whereby spawning adult population numbers are declining more rapidly than adult brooders, while recruitment of spawned offspring has not declined as much as recruitment of brooded offspring. As environmental variability and harsh conditions become more common due to human disturbance, future coral community demographics and dynamics, and the overall success of a particular life history strategy, will depend on the robustness of each species to this new stress regime during its vulnerable early life stages.

\section{ACKNOWLEDGMENTS}

A. C. Hartmann thanks Michael Latz, Mark Ohman, Nichole Price, Dimitri Deheyn, and Holland Elder for insightful conversations and comments on this manuscript, as well as Brenton Du and Joyce Huang for assistance with data collection. We also thank an anonymous reviewer for insightful comments. This work was supported by the NSF Graduate Research Fellowship Program (A. C. Hartmann), Future of Reefs in a Changing Environment project (Grant no. 244161; European Union; M. J. A. Vermeij), PADI Foundation (A. C. Hartmann), and the CARMABI Foundation, Willemstad, Curaçao. K. L. Marhaver was supported by NSF IOS Grants 0644438 and 1146880 (awarded to Mónica Medina).

\section{Literature Cited}

Allen, R. M., Y. M. Buckley, and D. J. Marshall. 2008. Offspring size plasticity in response to intraspecific competition: an adaptive maternal effect across life-history stages. American Naturalist 171:225-237.

Begon, M., C. R. Townsend, and J. L. Harper. 2006. Ecology: from individuals to ecosystems. Wiley Blackwell, Hoboken, New Jersey, USA.

Bernardo, J. 1996. The particular maternal effect of propagule size, especially egg size: patterns, models, quality of evidence and interpretations. American Zoologist 36:216-236.

Burgess, S. C., and D. J. Marshall. 2011. Are numbers enough? Colonizer phenotype and abundance interact to affect population dynamics. Journal of Animal Ecology 80:681687.
Burman, S. G., R. B. Aronson, and R. van Woesik. 2012. Biotic homogenization of coral assemblages along the Florida reef tract. Marine Ecology Progress Series 467:89-96.

Chesson, P. L., and R. R. Warner. 1981. Environmental variability promotes coexistence in lottery competitive systems. American Naturalist 117:923-943.

Crean, A. J., and D. J. Marshall. 2009. Coping with environmental uncertainty: dynamic bet hedging as a maternal effect. Philosophical Transactions of the Royal Society B 364:1087-1096.

Crean, A. J., K. Monro, and D. J. Marshall. 2011. Fitness consequences of larval traits persist across the metamorphic boundary. Evolution 65:3079-3089.

Diederich, C. M., J. N. Jarrett, O. R. Chaparro, C. J. Segura, S. M. Arellano, and J. A. Pechenik. 2011. Low salinity stress experienced by larvae does not affect post-metamorphic growth or survival in three calyptraeid gastropods. Journal of Experimental Marine Biology and Ecology 397:94-105.

Edmunds, P. J., R. D. Gates, and D. F. Gleason. 2001. The biology of larvae from the reef coral Porites astreoides, and their response to temperature disturbances. Marine Biology 139:981-989.

Emlet, R. B., and O. Hoegh-Guldberg. 1997. Effects of egg size on postlarval performance: experimental evidence from a sea urchin. Evolution 51:141-152.

Figueiredo, J., A. H. Baird, M. F. Cohen, J. F. Flot, T. Kamiki, T. Meziane, M. Tsuchiya, and H. Yamasaki. 2012. Ontogenetic change in the lipid and fatty acid composition of scleractinian coral larvae. Coral Reefs 31:613-619.

Gebauer, P., K. Paschke, and K. Anger. 1999. Costs of delayed metamorphosis: reduced growth and survival in early juveniles of an estuarine grapsid crab, Chasmagnathus granulata. Journal of Experimental Marine Biology and Ecology 238:271-281.

Green, D. H., P. J. Edmunds, and R. C. Carpenter. 2008. Increasing relative abundance of Porites astreoides on Caribbean reefs mediated by an overall decline in coral cover. Marine Ecology Progress Series 359:1-10.

Hamdoun, A., and D. Epel. 2007. Embryo stability and vulnerability in an always changing world. Proceedings of the National Academy of Sciences USA 104:1745-1750.

Harii, S., K. Nadaoka, M. Yamamoto, and K. Iwao. 2007. Temporal changes in settlement, lipid content and lipid composition of larvae of the spawning hermatypic coral Acropora tenuis. Marine Ecology Progress Series 346:89-96.

Hilborn, R., and M. Mangel. 1997. The ecological detective: confronting models with data. Princeton University Press, Princeton, New Jersey, USA.

Hughes, T. P., and J. E. Tanner. 2000. Recruitment failure, life histories, and long-term decline of Caribbean corals. Ecology 81:2250-2263.

Kinsey, D. W., and E. Kinsey. 1967. Diurnal changes in oxygen content of the water over the coral reef platform at Heron I. Marine and Freshwater Research 18:23-34.

Knowlton, N. 2001. The future of coral reefs. Proceedings of the National Academy of Sciences USA 98:5419-5425.

Marhaver, K. L., M. J. A. Vermeij, F. Rohwer, and S. A. Sandin. 2013. Janzen-Connell effects in a broadcast-spawning Caribbean coral: distance-dependent survival of larvae and settlers. Ecology 94:146-160.

Marshall, D. J., C. N. Cook, and R. B. Emlet. 2006. Offspring size effects mediate competitive interactions in a colonial marine invertebrate. Ecology 87:214-225.

Marshall, D. J., and M. J. Keough. 2009. Does interspecific competition affect offspring provisioning? Ecology 90:487-495.

Marshall, D. J., and S. G. Morgan. 2011. Ecological and evolutionary consequences of linked life-history stages in the sea. Current Biology 21:R718-R725.

McCormick, M. I., and B. W. Molony. 1992. Effects of feeding history on the growth characteristics of a reef fish at settlement. Marine Biology 114:165-173. 
Merilä, J., and E. Svensson. 1997. Are fat reserves in migratory birds affected by condition in early life? Journal of Avian Biology 28:1279-1286.

Moran, A. L., and R. B. Emlet. 2001. Offspring size and performance in variable environments: field studies on a marine snail. Ecology 82:1597-1612.

Morse, D. E., A. N. C. Morse, P. T. Raimondi, and N. Hooker. 1994. Morphogen-based chemical flypaper for Agaricia humilis coral larvae. Biological Bulletin 186:172-181.

Mousseau, T. A., and C. W. Fox. 1998. The adaptive significance of maternal effects. Trends in Ecology and Evolution 13:403-407.

Parker, G. A., and M. Begon. 1986. Optimal egg size and clutch size: effects of environment and maternal phenotype. American Naturalist 128:573-592.

Parsons, K. E. 1998. The role of dispersal ability in the phenotypic differentiation and plasticity of two marine gastropods: II. Growth. Journal of Experimental Marine Biology and Ecology 221:1-25.

Pechenik, J. A. 2006. Larval experience and latent effectsmetamorphosis is not a new beginning. Integrative and Comparative Biology 46:323-333.

Raimondi, P. T., and A. N. C. Morse. 2000. The consequences of complex larval behavior in a coral. Ecology 81:3193-3211.

Randall, C. J., and A. M. Szmant. 2009. Elevated temperature reduces survivorship and settlement of the larvae of the Caribbean scleractinian coral, Favia fragum (Esper). Coral Reefs 28:537-545.

Ross, C., R. Ritson-Williams, K. Olsen, and V. J. Paul. 2012. Short-term and latent post-settlement effects associated with elevated temperature and oxidative stress on larvae from the coral Porites astreoides. Coral Reefs 32:71-79.

Semlitsch, R. D., D. E. Scott, and J. H. Pechmann. 1988. Time and size at metamorphosis related to adult fitness in Ambystoma talpoideum. Ecology 69:184-192.

Smith, C. C., and S. D. Fretwell. 1974. Optimal balance between size and number of offspring. American Naturalist 108:499-506.

Strathmann, R. R., T. P. Hughes, A. M. Kuris, K. C. Lindeman, S. G. Morgan, J. M. Pandolfi, and R. R. Warner. 2002. Evolution of local recruitment and its consequences for marine populations. Bulletin of Marine Science 70:377-396.
Szmant, A. M. 1991. Sexual reproduction by the Caribbean reef corals Montastrea annularis and $M$. cavernosa. Marine Ecology Progress Series 74:13-25.

Szmant, A. M., E. Weil, M. W. Miller, and D. E. Colon. 1997. Hybridization within the species complex of the scleractinian coral Montastraea annularis. Marine Biology 129:561-572.

Thiyagarajan, V., J. A. Pechenik, L. A. Gosselin, and P. Y. Qian. 2007. Juvenile growth in barnacles: combined effect of delayed metamorphosis and sub-lethal exposure of cyprids to low-salinity stress. Marine Ecology Progress Series 344:173184.

Thorson, G. 1950. Reproductive and larval ecology of marine bottom invertebrates. Biological Revues 24:1-45.

Uller, T. 2008. Developmental plasticity and the evolution of parental effects. Trends in Ecology and Evolution 23:432438.

Van Moorsel, G. W. N. M. 1983. Reproductive strategies in two closely related stony corals (Agaricia, Scleractinia). Marine Ecology Progress Series 13:273-284.

Vermeij, M. J. A., J. Bakker, N. van der Hal, and R. P. M. Bak. 2011. Juvenile coral abundance has decreased by more than $50 \%$ in only three decades on a small Caribbean island. Diversity 3:296-307.

Vermeij, M. J. A., N. D. Fogarty, and M. W. Miller. 2006. Pelagic conditions affect larval behavior, survival, and settlement patterns in the Caribbean coral Montastraea faveolata. Marine Ecology Progress Series 310:119-128.

Vermeij, M. J. A., and S. A. Sandin. 2008. Density-dependent settlement and mortality structure the earliest life phases of a coral population. Ecology 89:1994-2004.

Vermeij, M. J. A., J. E. Smith, C. M. Smith, R. V. Thurber, and S. A. Sandin. 2009. Survival and settlement success of coral planulae: independent and synergistic effects of macroalgae and microbes. Oecologia 159:325-336.

Videla, J. A., O. R. Chaparro, R. J. Thompson, and I. I. Concha. 1998. Role of biochemical energy reserves in the metamorphosis and early juvenile development of the oyster Ostrea chilensis. Marine Biology 132:635-640.

Wendt, D. E. 2000. Energetics of larval swimming and metamorphosis in four species of Bugula (Bryozoa). Biological Bulletin 198:346-356.

\section{Supplemental Material}

\section{Appendix}

Parameter estimations and maximum-likelihood values for experiments depicted in Figs. 1-3 (Ecological Archives E094-179-A1). 